\title{
A Many-Country, Many-Good Model of Labor Market Rigidities as a Source of Comparative Advantage
}

\section{Citation}

Cuñat, Alejandro and Marc J. Melitz. 2009. A many-country, many-good model of labor market rigidities as a source of comparative advantage. Journal of the European Economic Association 8(2-3): 434-441.

\section{Published Version}

doi:10.1111/j.1542-4774.2010.tb00514.x

\section{Permanent link}

http://nrs.harvard.edu/urn-3:HUL.InstRepos:9299644

\section{Terms of Use}

This article was downloaded from Harvard University's DASH repository, and is made available under the terms and conditions applicable to Open Access Policy Articles, as set forth at http:// nrs.harvard.edu/urn-3:HUL.InstRepos:dash.current.terms-of-use\#OAP

\section{Share Your Story}

The Harvard community has made this article openly available.

Please share how this access benefits you. Submit a story.

\section{Accessibility}




\title{
A Many-Country, Many-Good Model of Labor Market Rigidities as a Source of Comparative Advantage*
}

\author{
Alejandro Cuñat \\ University of Vienna
}

\author{
Marc J. Melitz \\ Harvard University
}

October 9, 2009

\begin{abstract}
We extend the theoretical framework in Cuñat and Melitz (2007) to a many-country setup where countries exhibit different degrees of labor market flexibility. We rely on the insights from a recent paper by Costinot (2009) to obtain precise predictions about comparative advantage in this setting: countries with more flexible labor markets specialize in more volatile industries.
\end{abstract}

${ }^{*}$ We thank (without implicating) Pol Antràs for comments and Arnaud Costinot for a very helpful discussion. Cuñat gratefully acknowledges financial support from Spain's CICYT (ECO2008-04669). 


\section{Introduction}

There is a long tradition in international trade theory of studying issues related to the labor market and its imperfections. The classic papers by Brecher (1974a, 1974b), the contributions of Matusz (1996), Saint-Paul (1997), Davis (1998a, 1998b), Brügemann (2003) and Davidson et al. (1999), and the very recent work by Davis and Harrigan (2008), Felbermayr et al. (2008), Helpman and Itskhoki (2008), and Helpman et al. (2008) exemplify, among others, this long-standing interest in the workings of open-economy models with different types of labor market frictions. Those labor market frictions are typically characterized by a detailed modeling of the country-level labor market institutions. On the empirical side, Cuñat and Melitz (2007) show that international differences in labor market flexibility do constitute an important source of comparative advantage: evidence for a large sample of countries confirms that the exports of countries with more flexible labor markets are biased towards high-volatility sectors, as cross-country differences in labor market regulation affect how firms can adjust to idiosyncratic shocks.

In this paper we extend the theoretical framework in Cuñat and Melitz (2007). In comparison with many of the aforementioned references, we treat labor market institutions in a relatively coarse way. The trade-off is that we can analyze the pattern of specialization in a setting with many goods and countries that exhibit different degrees of labor market flexibility. This allows for a closer integration with the associated empirical work. We rely on the insights from a recent paper by Costinot (2009) to obtain precise predictions about comparative advantage in a manycountry setting. This allows us to generalize the predictions from the two-country version of our model developed in Cuñat and Melitz (2007): countries with relatively more flexible labor markets specialize in relatively more volatile industries.

In general, generating precise predictions for the pattern of comparative advantage in a Ricardian setting with multiple goods and countries has been problematic. The classic contributions by Deardorff (1980) and Dixit and Norman (1980), based on the duality approach, provide a solution to the many-good issue, but leave the many-country problem open. Eaton and Kortum (2002) show how a probabilistic approach to such a Ricardian model can yield precise predictions for trade flows and relative prices as well as a tractable computable general equilibrium model of trade; but such a probabilistic approach sidesteps the determination of the pattern of specialization across countries and sectors (based on technology differences across countries). Costinot (2009) develops a general open-economy framework with many countries, sectors, and factors that can be adapted to many 
more specific cases. The Ricardian version of his model focuses on the case where each country produces a single good, but he also mentions that this setup can be extended to the case where each country specializes in a continuum of goods, as initially analyzed by Dornbusch et al (1977) for the two country case. Once we solve for the effects of labor market flexibility on industry productivity, our model becomes a specific example of this extension. We provide a proof for this extension, which follows a very similar logic to the one originally developed by Costinot (2009). This proof is not specific to our particular institutional assumptions, and thus applies more generally as a multi-country extension of Dornbusch et al (1977) with complete specialization. In that equilibrium, every country specializes in a non-overlapping range of goods on the continuum, based on their country-level technology. As in Costinot (2009), the multi-country extension imposes a strong assumption on the pattern of cross-country differences in technology. That assumption is based on a unidimensional ordering of countries and sectors, each along a given characteristic. The key assumption is then one of log-supermodularity for country-industry TFP as a function of the country and industry characteristics. Given this, the open economy equilibrium solves an assignment problem of industries to countries (assigning production in that industry to a given country).

\section{The Model}

There are many countries, denoted by $c$. Each country is endowed with $L_{c}$ units of labor, which is supplied inelastically and internationally immobile. Preferences are identical across countries. Agents maximize utility over a large number of final goods, denoted by $i .{ }^{1}$ We think of each industry $i$ as a Cobb-Douglas aggregate of nontraded sectors $s$ :

$$
y(i)=\exp \left\{\int_{0}^{1} \ln y(i, s) d s\right\},
$$

where $y(i)$ denotes production of final good $i$. Each good $s$ is produced in turn with a continuum of nontraded intermediate goods:

$$
y(i, s)=\left[\int_{0}^{1} y(i, s, z)^{\frac{\varepsilon-1}{\varepsilon}} d z\right]^{\frac{\varepsilon}{\varepsilon-1}} .
$$

\footnotetext{
${ }^{1}$ We can think of these many goods as a continuum.
} 
Intermediate goods are produced according to the 'Ricardian' technology

$$
y(i, s, z)=e^{\pi} L(i, s, z)
$$

where $\pi$ is a stochastic term. Within each industry, $\pi$ is an iid draw from a common distribution $G_{i}($.$) , identical across countries, but different across industries, with mean 0$ and variance $\sigma^{2}(i)$. We will refer to $\sigma^{2}(i)$ as industry $i$ 's 'volatility'. This formulation emphasizes shocks to intermediate good producers on the production side; allowing instead for demand shocks in equation (1) would yield identical results to the ones we discuss below. As a given realization of the productivity draw $\pi$ uniquely identifies an intermediate good producer $z$, we now switch to the use of this draw $\pi$ as our index for the intermediate good. Without loss of generality we assume that the industries are ranked in order of increasing volatility so that $\sigma(i)$ is increasing in $i$.

Within each industry, there are 'flexible' and 'rigid' sectors $s$, denoted respectively by $\phi$ and $\rho$. We assume that a measure $\lambda_{c} \in[0,1]$ of sectors in industry $i$ are flexible $(s \in \phi)$, whereas a measure $\left(1-\lambda_{c}\right)$ are rigid $(s \in \rho)$. Labor is ex-ante perfectly mobile across sectors and industries. In a flexible sector, firms hire labor after uncertainty is realized. After the realization of $\pi$, production and commodity market clearing take place in a competitive setting. Rigid sectors must hire labor before uncertainty is realized, and the intermediate good producer is contractually committed to paying the hired number of workers the agreed wage (regardless of the realization of $\pi$ ). We assume labor market clearing: the wage $w$ is such that there is full employment. ${ }^{2}$ After the realization of $\pi$, production and commodity market clearing take place in a competitive setting, subject to the wage and employment restrictions. Rigid-sector intermediate goods producers anticipate this equilibrium, and adjust their contracted labor demand accordingly. Given ex-ante free entry into the intermediate goods sector, expected profits of the rigid-sector intermediate good producers are driven to zero.

\footnotetext{
${ }^{2}$ The presence of firm-specific productivity shocks does not affect aggregate outcomes. The law of large numbers ensures there is no aggregate uncertainty in the model.
} 


\section{Labor Market Flexibility, Volatility, and Productivity ${ }^{3}$}

\section{The Flexible Sector}

The appendix shows that for $s \in \phi$, the sector-level price is given by

$$
p_{\phi}(i, s)=\frac{w}{\tilde{\pi}_{\phi}(i, s)}
$$

where the flexible-sector average productivity level $\tilde{\pi}_{\phi}(i, s)$ is in-turn given by

$$
\tilde{\pi}_{\phi}(i, s)=\left[\int_{-\infty}^{\infty} e^{(\varepsilon-1) \pi} d G_{i}(\pi)\right]^{\frac{1}{\varepsilon-1}} .
$$

\section{The Rigid Sector}

The appendix shows that for $s \in \rho$, the sector-level price is given by

$$
p_{\rho}(i, s)=\frac{w}{\tilde{\pi}_{\rho}(i, s)}
$$

where the rigid-sector average productivity $\tilde{\pi}_{\rho}(i, s)$ is in-turn given by

$$
\tilde{\pi}_{\rho}(i, s)=\left[\int_{-\infty}^{\infty} e^{\frac{(\varepsilon-1)}{\varepsilon} \pi} d G_{i}(\pi)\right]^{\frac{\varepsilon}{\varepsilon-1}}
$$

In general, flexible sectors are more productive than rigid sectors $\left(\tilde{\pi}_{\phi}(i, s) \geq \tilde{\pi}_{\rho}(i, s)\right)$, due to their ability to reallocate labor from low-to high-productivity firms. Notice that $\tilde{\pi}_{\phi}(i, s)=\tilde{\pi}_{\rho}(i, s)$ only if volatility is zero $\left(\sigma^{2}(i)=0\right)$ : in this case, obviously, the ability of the flexible sector to reallocate labor is irrelevant.

\section{Aggregation}

In order to simplify the analysis, we parametrize the productivity draws to the normal distribution, thus assuming that $\pi \sim N\left[0, \sigma^{2}(i)\right]$ in industry $i$ (the distribution $G_{i}$ is Normal with mean 0 and

\footnotetext{
${ }^{3}$ The analysis of the flexible and rigid sectors follows Cuñat and Melitz (2007). For completeness, we revisit some analytics in the appendix.
} 
variance $\left.\sigma^{2}(i)\right)$. This yields average sector productivity

$$
\begin{aligned}
& \tilde{\pi}_{\phi}(i, s)=\exp \left\{(\varepsilon-1) \frac{\sigma^{2}(i)}{2}\right\} \\
& \tilde{\pi}_{\rho}(i, s)=\exp \left\{\frac{(\varepsilon-1)}{\varepsilon} \frac{\sigma^{2}(i)}{2}\right\} .
\end{aligned}
$$

With flexible and rigid sectors within each industry, autarky final-good prices in country $c$ are given by

$$
p_{c}(i)=\exp \left\{\lambda_{c} \ln p_{\phi}+\left(1-\lambda_{c}\right) \ln p_{\rho}\right\}=\frac{w_{c}}{\tilde{\pi}\left(\lambda_{c}, i\right)}
$$

where industry $i$ productivity in country $c$, now depends on that country's labor market flexibility $\lambda_{c}:$

$$
\tilde{\pi}\left(\lambda_{c}, i\right)=\exp \left\{\left[\frac{(\varepsilon-1)^{2}}{\varepsilon} \lambda_{c}+\frac{(\varepsilon-1)}{\varepsilon}\right] \frac{\sigma^{2}(i)}{2}\right\} .
$$

Not surprisingly, the industry's productivity varies positively with the degree of flexibility $\lambda_{c}$.

\section{Comparative Advantage}

The discussion above shows how our model can be analyzed in reduced form as a standard Ricardian model where country $c$ technology for producing good $i$ is given by the productivity term $\tilde{\pi}\left(\lambda_{c}, i\right)$ (the inverse unit input requirement). This function uniquely summarizes the Ricardian technology differences across sectors and countries. In what follows, we take this function as a primitive for the reduced form version of the model. This reduced form is a "modified" version of the R-Economy developed in Costinot (2009), where assumption 0 is not imposed, and thus accommodates the case where countries specialize in a continuum of goods. Our main result regarding the pattern of specialization in the open follows directly from the following proposition:

Proposition 1 Consider a multi-country Ricardian world with a single production factor and constant returns to scale such that the output per unit input in sector $i, \tilde{\pi}\left(\lambda_{c}, i\right)$, is log-supermodular in both arguments. Then the open economy equilibrium with free trade must feature positive assortative matching between countries (ranked by $\lambda_{c}$ ) and the range of sectors $\left[i_{c, \min }, i_{c, \max }\right]$ in which they specialize such that $\lambda_{c}>\lambda_{c^{\prime}} \Longrightarrow i_{c, \min } \geq i_{c^{\prime}, \max }$.

Note that this open economy equilibrium features complete specialization, such that countries with different country charasteristics produce at most a single good in common. The proof of the proposition follows immediately from 
Lemma 1 Let $i$ be a good that is produced by $c$, where $\lambda_{c}>\lambda_{c^{\prime}}$; then $c^{\prime}$ cannot produce any $i^{\prime}>i$.

Proof. Assume that $c$ produces $i$ and does not produce $i^{\prime}$, and that $c^{\prime}$ produces $i^{\prime}$. Then it must be the case that $w_{c^{\prime}} / \tilde{\pi}\left(\lambda_{c^{\prime}}, i^{\prime}\right)<w_{c} / \tilde{\pi}\left(\lambda_{c}, i^{\prime}\right)$. Then, by log-supermodularity, $c^{\prime}$ must produce $i$ cheaper than $c$ :

$$
\frac{\tilde{\pi}\left(\lambda_{c}, i^{\prime}\right)}{\tilde{\pi}\left(\lambda_{c}, i\right)}>\frac{\tilde{\pi}\left(\lambda_{c^{\prime}}, i^{\prime}\right)}{\tilde{\pi}\left(\lambda_{c^{\prime}}, i\right)}
$$

This contradicts our original statement.

In the context of our model, the productivity function $\tilde{\pi}\left(\lambda_{c}, i\right)$ is log-supermodular since it is strictly positive and twice continuously differentiable with $\partial^{2} \ln \tilde{\pi}\left(\lambda_{c}, i\right) /\left(\partial \lambda_{c} \partial i\right)>0$. Thus, under free trade, countries with more flexible labor markets specialize in segments of final goods subject to a higher volatility. The average volatility of the production structure of a country with a flexible labor market must therefore be higher than that of a country with a rigid labor market. ${ }^{4}$

\section{Concluding Remarks}

We have shown how the insights developed in Cuñat and Melitz (2007) within a two-country model can be extended to a many-country setting, thus providing a closer parallel with the empirical work that is developed therein. The assumptions needed to generalize the results from a two-country Ricardian model to many countries are not specific to our particular institutional framework, and can thus be applied more generally to multi-country Ricardian frameworks that satisfy the key log-supermodularity condition for country-sector technology differences.

\section{References}

[1] Brecher, R.A. (1974a): "Minimum Wage Rates and the Pure Theory of International Trade," Quarterly Journal of Economics, 88(1), pp. 98-116.

[2] Brecher, R.A. (1974b): "Optimal Commercial Policy for a Minimum-Wage Economy," Journal of International Economics, 4(2), pp. 139-149.

[3] Brügemann, B. (2003): "Trade Integration and the Political Support for Labor Market Rigidity," manuscript, Yale.

[4] Costinot, A. (2009): "An Elementary Theory of Comparative Advantage," Econometrica, 77 (4), pp. 1165-1192.

\footnotetext{
${ }^{4}$ If two or more countries share the same labor flexibility parameter $\lambda_{c}$, then the analysis proceeds by treating those countries as a single group that aggregates the labor endowment, with that same country parameter $\lambda_{c}$. The pattern of specialization within the group remains indeterminate.
} 
[5] Cuñat, A. and M.J. Melitz (2007): "Volatility, Labor Market Flexibility, and the Pattern of Comparative Advantage," NBER Working Paper 13062.

[6] Davidson, C., L. Martin, and S. Matusz (1999): "Trade and Search Generated Unemployment," Journal of International Economics, 48, pp. 271-299.

[7] Davis, D.R. (1998a): "Does European Unemployment Prop up American Wages? National Labor Markets and Global Trade," American Economic Review, 88(3), pp. 478-494.

[8] Davis, D.R. (1998b): "Technology, Unemployment, and Relative Wages in a Global Economy," European Economic Review, 42, pp. 1613-1633.

[9] Davis, D.R. and J. Harrigan (2008): "Good Jobs, Bad Jobs, and Trade Liberalization," manuscript, Columbia University.

[10] Deardorff, A.V. (1980): "The General Validity of the Law of Comparative Advantage," Journal of Political Economy, 88 (5), pp. 941-957.

[11] Dixit, A. and V. Norman (1980): Theory of International Trade, Cambridge University Press.

[12] Dornbusch, R., S. Fischer, and P.A. Samuelson (1977): "Comparative Advantage, Trade, and Payments in a Ricardian Model with a Continuum of Goods," American Economic Review, 67(5), pp. 823-839.

[13] Eaton, J., and S. Kortum (2002) Technology, Geography, and Trade, Econometrica 70, pp. 1741-1779.

[14] Felbermayr, G., J. Prat and H.J. Schmerer (2008): "Globalization and Labor Market Outcomes: Wage Bargaining, Search Frictions, and Firm Heterogeneity," IZA DP No. 3363.

[15] Helpman, E. and O. Itskhoki (2009): "Labor Market Rigidities, Trade and Unemployment," manuscript, Harvard University.

[16] Helpman, E., O. Itskhoki and S.J. Redding (2008): "Inequality and Unemployment in a Global Economy," manuscript, Harvard University.

[17] Matusz, S.J. (1996): "International Trade, the Division of Labor, and Unemployment" International Economic Review, 37(1), pp. 71-84.

[18] Saint-Paul, G. (1997): "Is Labour Rigidity Harming Europe's Competitiveness? The Effect of Job Protection on the Pattern of Trade and Welfare," European Economic Review, 41, pp. 499-506. 


\section{Appendix}

\section{A The Flexible Sector}

Let $p_{\phi, \pi}(i, s, z)$ be the price of the intermediate good $z$ in sector $s \in \phi$ receiving a productivity draw $\pi$. That good is priced at marginal cost $e^{-\pi} w$. The sector-level price is then given by the C.E.S. aggregator of the intermediate good prices:

$$
\begin{aligned}
p_{\phi}(i, s) & =\left[\int_{-\infty}^{\infty} p_{\phi, \pi}(i, s, z)^{1-\varepsilon} d G_{i}(\pi)\right]^{\frac{1}{1-\varepsilon}}, \\
& =\frac{w}{\left[\int_{-\infty}^{\infty} e^{(\varepsilon-1) \pi} d G_{i}(\pi)\right]^{\frac{1}{\varepsilon-1}}},
\end{aligned}
$$

where $\tilde{\pi}_{\phi}(i, s) \equiv\left[\int_{-\infty}^{\infty} e^{(\varepsilon-1) \pi} d G_{i}(\pi)\right]^{\frac{1}{\varepsilon-1}}$ represents the productivity level in a flexible sector $s \in \phi$.

\section{B The Rigid Sector}

The law of large numbers ensures that there is no aggregate uncertainty within each sector. We assume that agents hold a diversified portfolio across firms and hence that firms maximize expected profits. Given that all intermediate-good producers in a sector are ex-ante identical, there will be no variation in the employment levels $L_{\rho}(i, s, z)$ across producers. Of course, their prices $p_{\rho, \pi}(i, s, z)$ and output levels $y_{\rho, \pi}(i, s, z)$ will vary with their ex-post productivity draw $\pi$.

The ex-ante zero-profit condition for an intermediate good producers equates its known labor cost with expected revenue, hence

$$
w L_{\rho}(i, s, z)=\int_{-\infty}^{\infty} p_{\rho, \pi}(i, s, z) y_{\rho, \pi}(i, s, z) d G_{i}(\pi)
$$

Market clearing for each intermediate good equates ex-post supply and demand:

$$
e^{\pi} L_{\rho}(i, s, z)=\left[\frac{p_{\rho, \pi}(i, s, z)}{p_{\rho}(i, s)}\right]^{-\varepsilon} y_{\rho}(i, s)
$$

where the sector level price $p_{\rho}(i, s)$ is given by the C.E.S. aggregator of the intermediate good prices:

$$
p_{\rho}(i, s)=\left[\int_{-\infty}^{\infty} p_{\rho, \pi}(i, s, z)^{1-\varepsilon} d G_{i}(\pi)\right]^{\frac{1}{1-\varepsilon}} .
$$


Jointly, these equations (B.1), (B.2), and (B.3) determine the sector-level price

$$
p_{\rho}(i, s)=\frac{w}{\left[\int_{-\infty}^{\infty} e^{\frac{(\varepsilon-1)}{\varepsilon} \pi} d G_{i}(\pi)\right]^{\frac{\varepsilon}{\varepsilon-1}}},
$$

where $\tilde{\pi}_{\rho}(i, s) \equiv\left[\int_{-\infty}^{\infty} e^{\frac{(\varepsilon-1)}{\varepsilon} \pi} d G_{i}(\pi)\right]^{\frac{\varepsilon}{\varepsilon-1}}$ represents the productivity level in a rigid sector $s \in \rho$. 